Gráficos del artículo

\title{
LOS INMIGRANTES ANTE LA PUBLICIDAD ESPECIALIZADA Y SU INCIDENCIA EN SU INTEGRACIÓN Y CONSUMO
}

Gráfico 1. Compra de servicio o producto anunciado en la prensa inmigrante (en porcentaje)

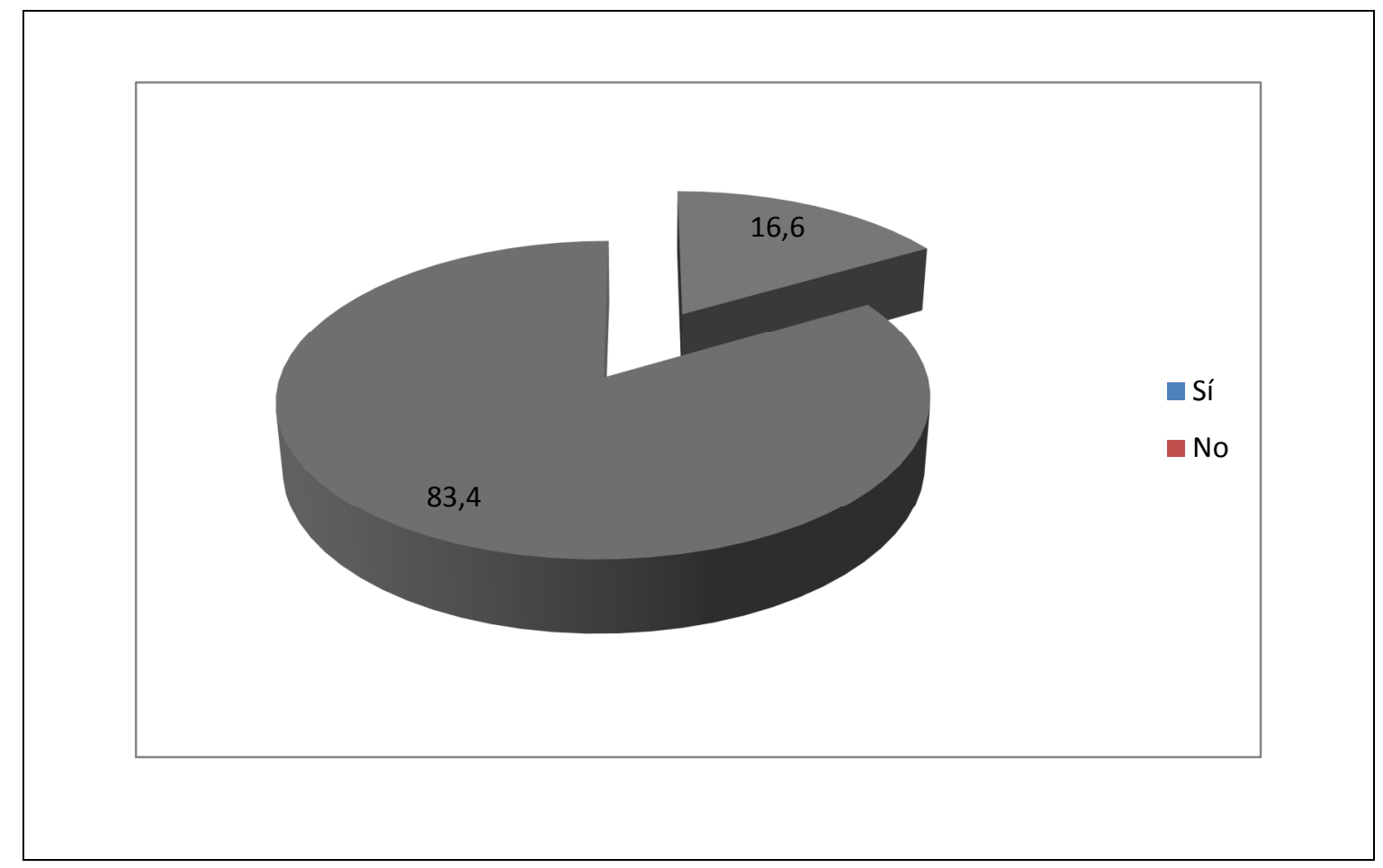

Fuente: elaboración propia. 
Gráfico 2. Motivación de la compra de servicio o producto anunciado en la prensa inmigrante (en porcentaje)

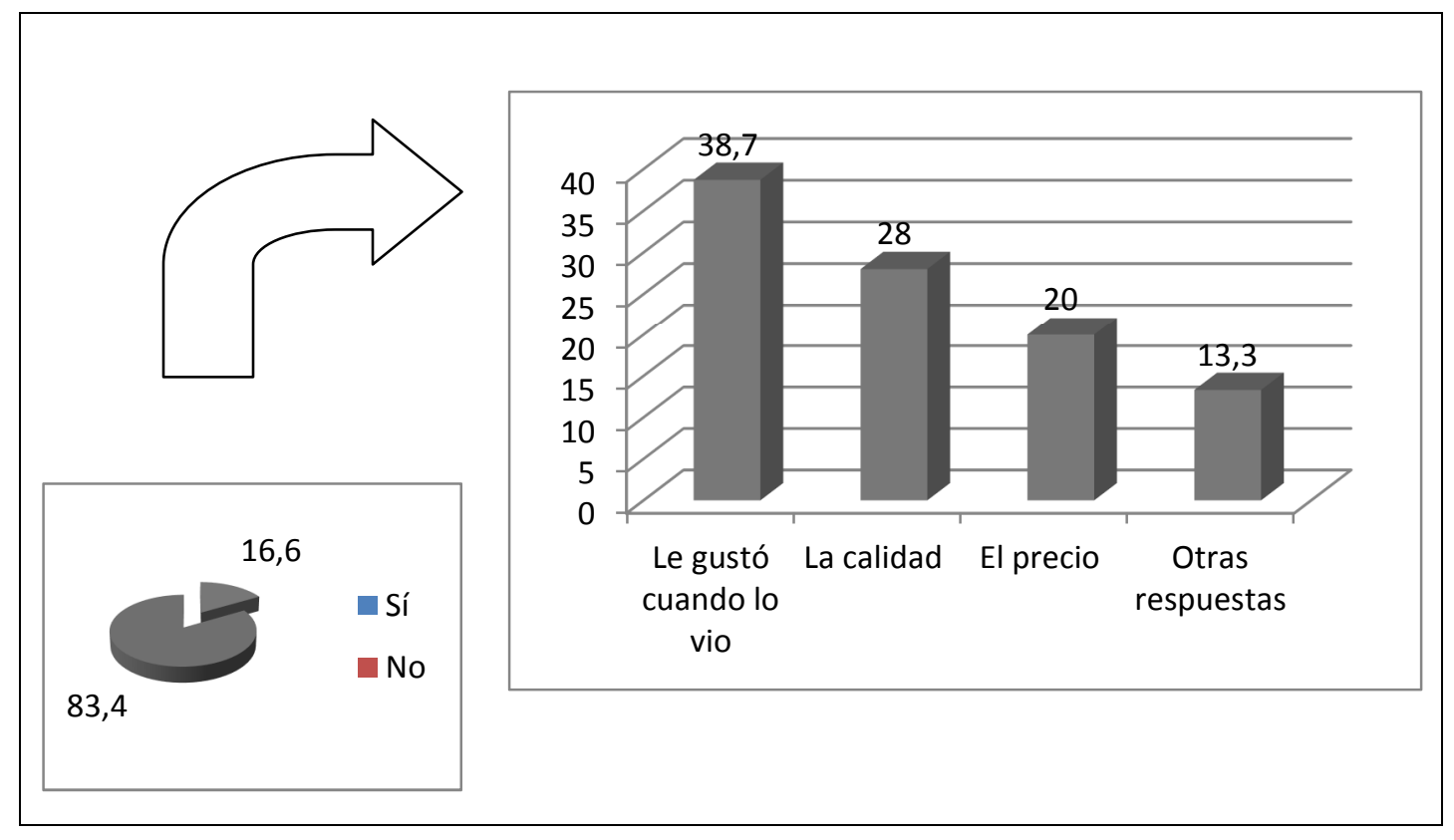

Fuente: elaboración propia. 
Gráfico 3. Valoración de personas inmigrantes en la publicidad (en porcentaje)

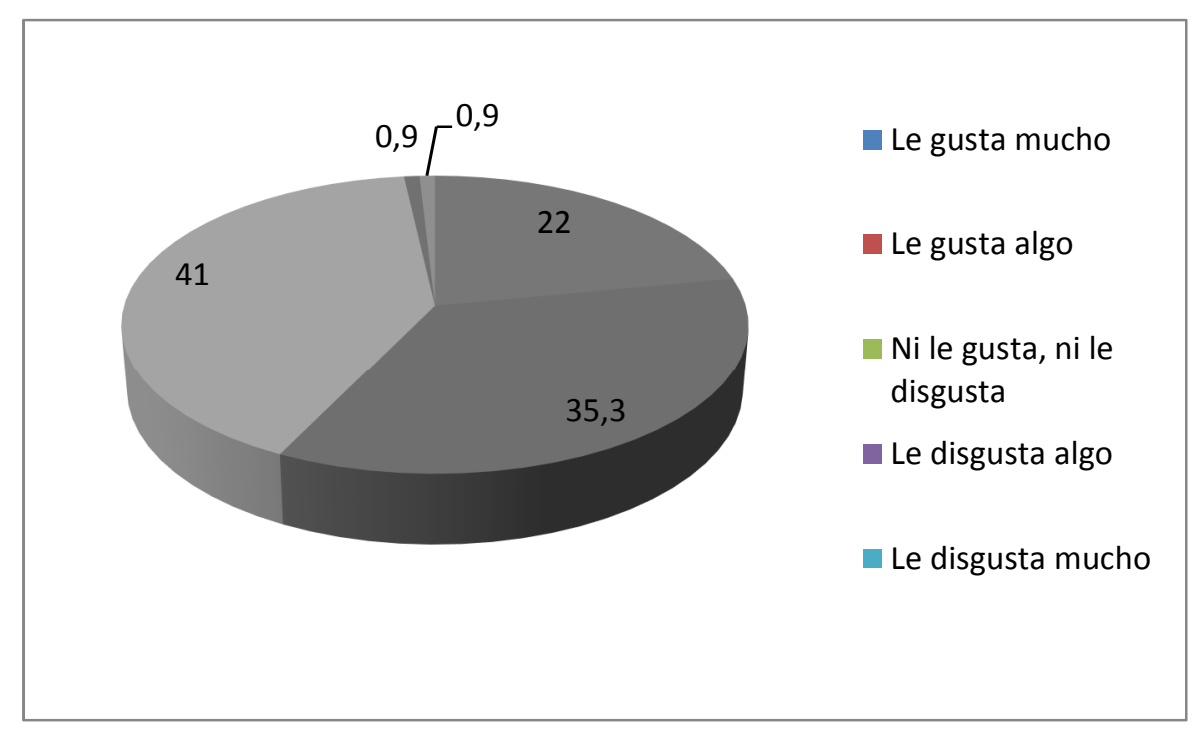

Fuente: elaboración propia. 
Tabla 1. Valoración de personas inmigrantes en la publicidad según nacionalidades (en porcentaje)

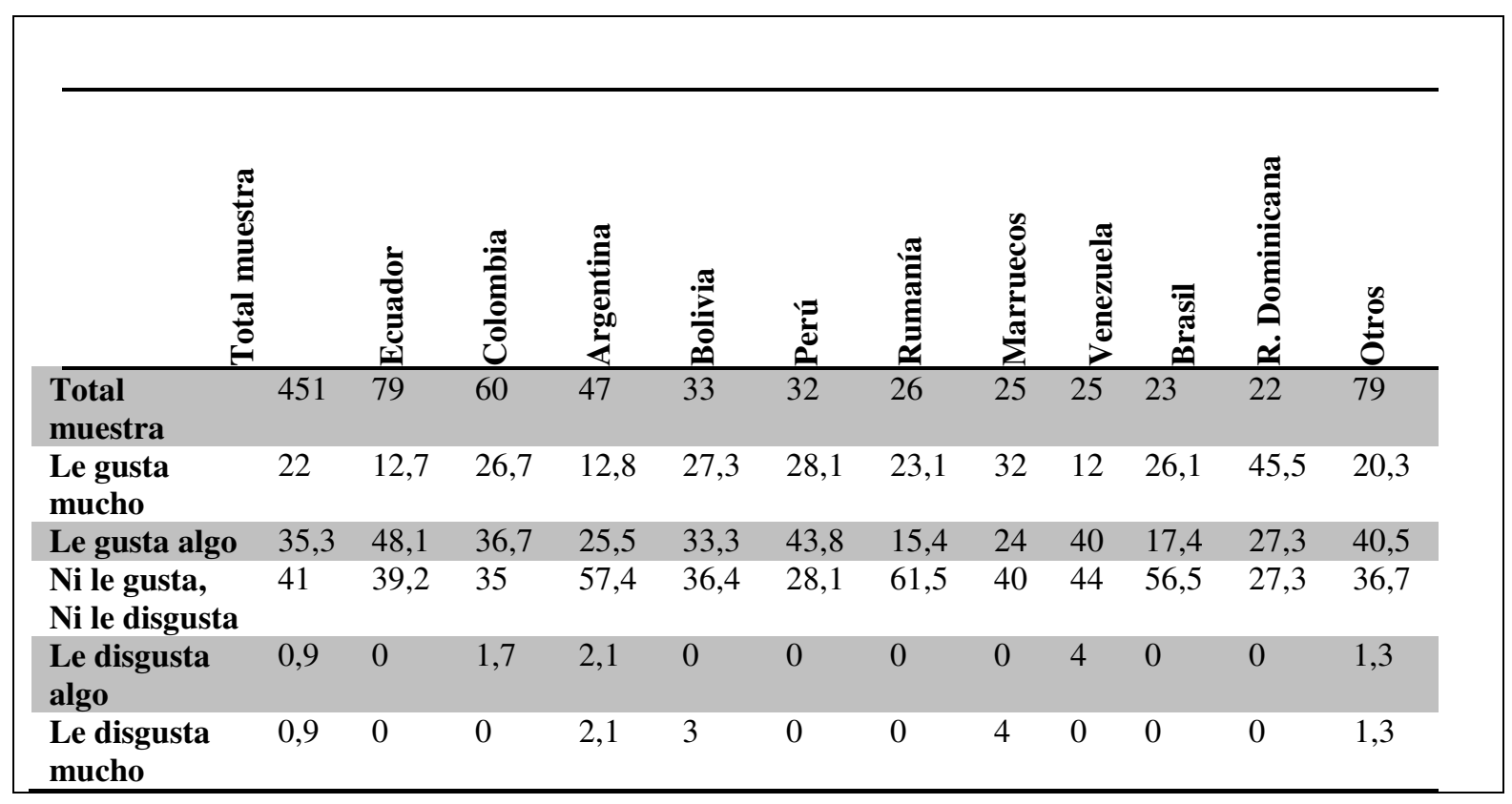

Fuente: elaboración propia. 
Gráfico 4. Grado de acuerdo con aparición de personas inmigrantes en publicidad

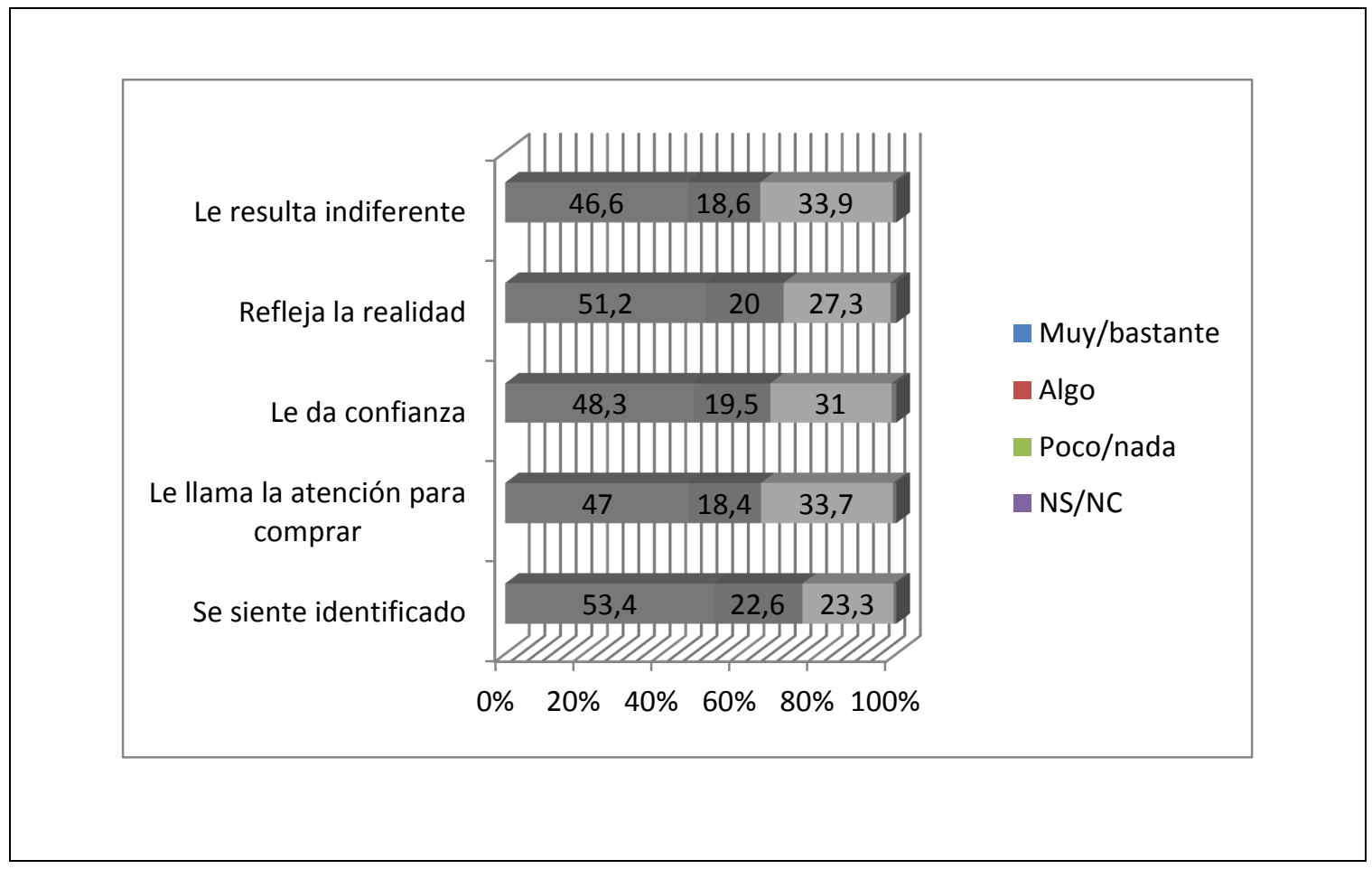

Fuente: elaboración propia. 
Tabla 2. Grado de acuerdo con aparición de personas inmigrantes en publicidad por sexo, edad y año de llegada (en porcentaje)

\begin{tabular}{|c|c|c|c|c|c|c|c|c|}
\hline & \multirow[t]{2}{*}{ TOTAL } & \multicolumn{2}{|c|}{ SEXO } & \multicolumn{2}{|c|}{ EDAD } & \multicolumn{3}{|c|}{ AÑO DE LLEGADA } \\
\hline & & Hombre & Mujer & $\begin{array}{l}15-34 \\
\text { años }\end{array}$ & $\begin{array}{l}35-54 \\
\text { años }\end{array}$ & $\begin{array}{l}2000 \text { o } \\
\text { antes }\end{array}$ & $\begin{array}{l}2001- \\
2005\end{array}$ & $\begin{array}{l}\text { Después } \\
\text { de } 2005\end{array}$ \\
\hline Total & 451 & 218 & 233 & 229 & 222 & 114 & 175 & 162 \\
\hline $\begin{array}{l}\text { Se siente } \\
\text { identificado }\end{array}$ & 53,4 & 51,4 & 55,4 & 54,1 & 52,7 & 50,9 & 50,9 & 58 \\
\hline $\begin{array}{l}\text { Le llama más la } \\
\text { atención para } \\
\text { comprar }\end{array}$ & 47 & 46,3 & 47,6 & 46,7 & 47,3 & 45,6 & 49,7 & 45,1 \\
\hline $\begin{array}{l}\text { Le da más } \\
\text { confianza }\end{array}$ & 48,3 & 46,3 & 50,2 & 47,2 & 49,5 & 46,5 & 49,1 & 48,8 \\
\hline $\begin{array}{l}\text { Refleja más la } \\
\text { realidad }\end{array}$ & 51,2 & 50 & 52,4 & 52 & 50,5 & 51,8 & 50,3 & 51,9 \\
\hline $\begin{array}{l}\text { Le dan igual los } \\
\text { personajes que } \\
\text { aparezcan }\end{array}$ & 46,6 & 50,5 & 42,9 & 45,9 & 47,3 & 57 & 42,3 & 43,8 \\
\hline
\end{tabular}

Fuente: elaboración propia. 